\title{
Study of candidate genes for dyslexia in Brazilian individuals
}

M.C.C.M. Svidnicki ${ }^{1}$, C.A. Salgado ${ }^{2}$, R.F. Lima ${ }^{2}$, S.M. Ciasca ${ }^{2}$, R. Secolin ${ }^{3}$, M.C.A. Pomilio ${ }^{4}$, P.A. Junqueira ${ }^{4}$, M.S. Pinto ${ }^{4}$, M.M. Pereira ${ }^{4}$ and E.L. Sartorato ${ }^{1}$

${ }^{1}$ Centro de Biologia Molecular e Engenharia Genética, Universidade Estadual de Campinas, Campinas, SP, Brasil

${ }^{2}$ Departamento de Neurologia, Universidade Estadual de Campinas, Campinas, SP, Brasil

${ }^{3}$ Departamento de Genética Médica, Universidade Estadual de Campinas, Campinas, SP, Brasil

${ }^{4}$ Associação Terapêutica de Estimulação Auditiva e Linguagem, Jundiaí, SP, Brasil

Corresponding author: M.C.C.M. Svidnicki

E-mail: mcarolinasvid@gmail.com

Genet. Mol. Res. 12 (4): 5356-5364 (2013)

Received December 12, 2012

Accepted July 6, 2013

Published November 7, 2013

DOI http://dx.doi.org/10.4238/2013.November.7.10

ABSTRACT. Dyslexia or reading disability (RD) is the most common
childhood learning disorder and a significantly heritable trait. Many
recent studies have investigated the genetic basis of dyslexia, and
several candidate genes have been proposed. Among these, $D C D C 2$ and
KIAA0319 have emerged as the strongest candidate genes for dyslexia;
however studies have not provided uniformly supportive results. The
aim of this study was to assess the contribution of proposed candidate
genes to the molecular etiology of dyslexia in a Brazilian sample. Large
deletions and duplications in the candidate genes $D C D C 2, K I A A 0319$,
and $R O B O 1$ were investigated in 51 dyslexic subjects. Furthermore, a
family-based association study was performed to investigate whether
associations observed in other populations with variants in the 
DCDC2 and KIAA0319 genes were reproducible in Brazilian dyslexic individuals. Our analysis did not detect any deletions or duplications in the genes studied, and we found no evidence that the allelic variants in the two candidate genes were significantly associated with RD in our sample. Our data do not support a role of the DCDC2/KIAA0319 locus in influencing dyslexia as a categorical trait. Given the genetic complexity of dyslexia, it is plausible that both genes contribute to an increased risk, but the relative influence of these 2 genes on $\mathrm{RD}$ varies in different study samples, and/or depends on analytical approaches.

Key words: Dyslexia; Reading disability; Candidate genes; $D C D C 2$; KIAA0319

\section{INTRODUCTION}

Reading disability (RD), or developmental dyslexia, is a complex disorder that results from genetic and environmental factors. RD is characterized by difficulties with speed and accuracy of word decoding and with text comprehension. The prevalence of dyslexia in school-aged populations has been estimated to vary from 5-12\% (Snowling and Maughen, 2006; Schumacher et al., 2007).

At least 10 chromosomal regions have been associated with dyslexia (Scerri et al., 2010). Of these, the chromosome $6 \mathrm{p}$ region has been the most studied and been reported to be linked to RD or reading measures in multiple samples. The DYX2 locus on $6 \mathrm{p} 22$ harbors two separate clusters of genes that are physically closely linked with each other and are called NRSN1/DCDC2/KAAG1 and KIAA0319/TTRAP/THEM2. The DCDC2 and KIAA0319 genes have emerged as the strongest candidate genes for dyslexia.

Previous research has associated the $D C D C 2$ SNP rs 807724 with dyslexia in an American cohort (Meng et al., 2005). In addition, Meng et al. (2005) observed that approximately 17\% of dyslexics had a deletion of 2445 bp within intron 2 of DCDC2. In a German study, 2 other SNPs in $D C D C 2$ were associated with dyslexia (Schumacher et al., 2007). Brkanac et al. (2007) could not replicate the findings of the SNPs in the American cohort, but also found evidence for an association of dyslexia with the deletion. Ludwig et al. (2008) used both categorically and quantitatively related traits to investigate the association between $\mathrm{RD}$ and $D C D C 2$ intron 2 deletion and short tandem repeat (STR) variants, but did not detect a significant association between RD and these genetic variants. In contrast, Wilcke et al. (2009), studying an independent German sample, reported evidence for an association between the $D C D C 2$ intron 2 deletion variant and a dyseidetic diagnostic subtype characterized by major impairment of visual perception. Lind et al. (2010) recently reported a study supporting an association of 2 SNPs in DCDC2 with quantitative measures in Australian families that were unselected for reading impairment.

Most of the genetic associations with dyslexia cluster around the $5^{\prime}$ end of the KIAA0319 gene and generally show the same allelic trends across independent studies (Francks et al., 2004, Cope et al., 2005; Schumacher et al., 2007; Luciano et al., 2007; Paracchini et al., 2008; Couto et al., 2009; Dennis et al., 2009; Wilcke et al., 2009).

Francks et al. (2004) identified 1 main RD risk haplotype comprising 3 SNPs (rs4504469, rs 2038137, and rs2143340) with a frequency of $12 \%$ in families from the United Kingdom and 
the United States. Functional studies have shown that this haplotype is associated with decreased expression of KIAA0319 (Paracchini et al., 2006). Cope et al. (2005) could not replicate the association to the G-C-C haplotype, and instead identified a $\mathrm{RD}$ risk haplotype consisting of different KIAA0319 markers. Luciano et al. (2007) also tested haplotypes consisting of these markers, and found evidence for an association of the haplotypes G-C-T and A-C-T, but not G-C-C, with poor reading. In a study by Couto et al. (2010), the RD risk haplotype described by Francks et al. (2004) was not associated with RD, whereas the A-A-T haplotype was associated with RD. The latter result is inconsistent with the studies by Francks et al. (2004) and Cope et al. (2005), which both reported that the A-A-T haplotype was associated with better reading performance.

Additional genes have also been proposed as dyslexia candidates: $\mathrm{XYX1C1}$ (NopolaHemmi et al., 2000), ROBO1 (Hannula-Jouppi et al., 2005), KIAA0319L (Couto et al., 2008), MLPR19, and C2ORF3 (Anthoni et al., 2007). Among them, DYX1C1, ROBO1, DCDC2, and KIAA0319 have been implicated in global brain-developmental processes such as neural migration and axonal guidance (Hivert et al., 2002, Meng et al., 2005, Wang et al., 2006; Paracchini et al., 2006). These results provide convincing evidence that these genes are interesting study targets on the basis of previous evidence from post-mortem studies in individuals with RD that have identified abnormalities in neuronal migration (Galaburda et al., 1985).

The aims of this study were to investigate large deletions and duplications in the $D C D C 2, K I A A 0319$, and ROBO1 genes and their proximal genes KAAG1, NRSN1, and $\mathrm{ROBO} 2$ that could explain the dyslexic phenotype and that could confirm that the associations found in other populations between the DCDC2 and KIAA0319 genes and dyslexia are replicable in Brazilian dyslexic individuals.

\section{MATERIAL AND METHODS}

\section{Patients}

Reading, spelling, and cognition phenotypes were evaluated in Brazilian individuals with complaints of reading and learning difficulties aged 7-14 years. Evaluations were conducted by trained psychologists and speech therapists from two institutions of the State of São Paulo: the Learning Disorders Laboratory (DISAPRE) from UNICAMP and the Therapeutic Association of Hearing and Language Stimulation (ATEAL). Both institutions receive referrals of children and adolescents with complaints of learning difficulties for multidisciplinary assessment and diagnosis.

Subjects underwent extensive neuropsychological testing: Scale of Intelligence Wechsler WISC-III (Figueiredo, 2001), Bender Visual Motor Gestalt Test (Sisto et al., 2005), and the Stroop Color Word Test (Stroop, 1935). In addition, a clinical interview [Child Behavior Checklist (CBCL)] was performed with the parents (Achenbach, 1991). Criteria of exclusion were the following: an intelligence quotient (IQ) of $<85$, an uncorrected peripheral hearing or vision disorder, or presence of other comorbid psychiatric conditions or neurological disorders affecting the development of reading and spelling abilities.

The language evaluation was performed by using reading and writing tests; a set of phonological tests included phonological awareness (Moojen et al., 2003), phonological working memory, and rapid automatized naming (Denckla and Rudel, 1974).

After parental informed consent had been obtained, 51 subjects diagnosed as dyslexics 
agreed to participate in this study. In addition, 5 normal readers with no history of learning difficulties were used as controls for deletion screening. To perform a family-based association study of the DCDC2 and KIAA0319 genes, parents and some siblings were also included in our sample, regardless of reading ability. Before blood collection, written informed consent was obtained from each participant. A total of 48 families composed the sample, and 2 of them had $>1$ affected child. Both parents of 36 dyslexic subjects were genotyped, whereas at least 1 parent was genotyped in 12 subjects. The Research Ethics Committee from Universidade Estadual de Campinas approved this study.

\section{DNA extraction and analysis}

DNA was extracted from peripheral blood samples by standard phenol-chloroform methods and quantified using Qubit (Applied Biosystems, Foster City, CA, USA); the DNA purity was assessed using the NanoDrop ND-1000 spectrophotometer (NanoDrop Technologies Inc., Detroit, MI, USA).

\section{MLPA reaction}

The DNA of the subjects was diluted in Tris-EDTA buffer solution to a final concentration of $250 \mathrm{ng} / \mu \mathrm{L}$. A multiplex ligation-dependent probe amplification (MLPA) reaction was performed, using the SALSA MLPA Kit P150 (MRC-Holland, Amsterdam, The Netherlands). The protocol was performed in accordance with that of Schouten et al. (2002), with minor modifications. For additional information, access MRC-Holland (2010), available at http://www.mrc-holland.com.

The P150 MLPA kit was designed to detect deletions/duplications in most exons of the $D C D C 2$ gene and some exons in the KIAAO319 and ROBO1 genes. In addition, probes were also used for the KAAG1 (close to DCDC2), NRSN1 (close to KIAA0319), and ROBO2 genes (close to $R O B O 1$ ).

Fragment analysis was performed on an ABI 310 Genetic Analyzer and results were analyzed using the GeneScan and Genotyper software (Applera Corporation, Applied Biosystems). Peak areas of the amplicons representing the respective probes were exported to a Microsoft Excel spreadsheet and calculations were performed according to the method described by Taylor et al. (2003). Probe ratios $<0.5$ or $>1.5$ were considered as indicative of a heterozygous deletion or duplication, respectively.

\section{Family-based association study in $D C D C 2$ and $K I A A 0319$}

\section{SNP selection and genotyping}

Polymorphism selection was performed on the basis of previous studies that have identified genetic associations with dyslexia in different countries. We analyzed 6 SNPs in $D C D C 2$ and 6 SNPs in KIAA0319. Only SNPs that passed quality control (QC) criteria (a call rate of $\geq 95 \%$ and frequency of the minor allele of $>0.05$ and Hardy-Weinberg disequilibrium $\mathrm{P}>0.01$ ) were used in the genetic analysis. The list of the selected SNPs and results of association or no association with dyslexia reported in previous studies are summarized in Table 1. 
Table 1. Genetic variants selected in $6 \mathrm{p}$ locus and references of previous studies.

\begin{tabular}{|c|c|c|c|c|c|}
\hline Gene & Genetic feature & SNP & Population studied & References of associations & References of negtive replications \\
\hline DCDC2 & Intronic & rs807701 & $\begin{array}{l}\text { German, British, } \\
\text { Canadian }\end{array}$ & $\begin{array}{l}\text { Schumacher et al., 2007; } \\
\text { Wilcke et al., } 2009\end{array}$ & $\begin{array}{l}\text { Harold et al., 2006; Brkanac et al., 2007; } \\
\text { Couto et al., } 2009\end{array}$ \\
\hline DCDC2 & Intronic & rs 807724 & $\begin{array}{l}\text { American, German, } \\
\text { British }\end{array}$ & $\begin{array}{l}\text { Meng et al., 2005; } \\
\text { Wilcke et al., 2009; } \\
\text { Newbury et al., 2011; } \\
\text { Serri et al., } 2011\end{array}$ & Harold et al., 2006; Brkanac et al., 2007 \\
\hline DCDC2 & Intronic & rs1419228 & $\begin{array}{l}\text { Australian, } \\
\text { Canadian }\end{array}$ & Lind et al., 2010 & Couto et al., 2009 \\
\hline $\mathrm{DCDC} 2$ & Exon 8 & rs9467075 & Australian & Lind et al., 2010 & \\
\hline DCDC2 & Intronic & rs 7765678 & Australian & Lind et al., 2010 & \\
\hline DCDC2 & Intronic & rs6922023 & Australian & Lind et al., 2010 & \\
\hline KIAA0319 & Intronic & rs6935076 & $\begin{array}{l}\text { British, Canadian, } \\
\text { Australian }\end{array}$ & $\begin{array}{l}\text { Cope et al., 2005; } \\
\text { Harold et al., 2006; } \\
\text { Luciano et al., 2007; } \\
\text { Serri et al., 2011; } \\
\text { Couto et al., 2009 }\end{array}$ & Brkanac et al., 2007 \\
\hline KIAA0319 & Intronic & rs2038137 & $\begin{array}{l}\text { British, American, } \\
\text { Canadian }\end{array}$ & $\begin{array}{l}\text { Francks et al., 2004; } \\
\text { Cope et al., 2005; } \\
\text { Harold et al., } 2006\end{array}$ & Serri et al., 2011; Couto et al., 2009 \\
\hline KIAA0319 & Intergenic & rs9461045 & $\begin{array}{l}\text { British, American, } \\
\text { German }\end{array}$ & $\begin{array}{l}\text { Francks et al., 2004; } \\
\text { Dennis et al., 2009; } \\
\text { Serri et al., } 2011\end{array}$ & Kirsten et al., 2012; Elbert et al., 2011 \\
\hline KIAA0319d & Intronic & rs2143340 & $\begin{array}{l}\text { British, American, } \\
\text { Australian }\end{array}$ & $\begin{array}{l}\text { Dennis et al., 2009; } \\
\text { Serri et al., 2011; } \\
\text { Francks et al., 2004; } \\
\text { Luciano et al., 2007 }\end{array}$ & \\
\hline KIAA0319 & Intronic & rs761100 & British, American & $\begin{array}{l}\text { Francks et al., 2004; } \\
\text { Harold et al., 2006 }\end{array}$ & \\
\hline KIAA0319 & Exon 4 & rs4504469 & $\begin{array}{l}\text { British, Indian, } \\
\text { Canadian }\end{array}$ & Cope et al., 2005 & $\begin{array}{l}\text { Venkatesh et al., 2011; Brkanac et al., 2007; } \\
\text { Couto et al., } 2009\end{array}$ \\
\hline
\end{tabular}

$\mathrm{d}=$ Within TTRAP gene.

Genotyping was performed using the OpenArray SNP Genotypingplatform (Applied Biosystems), which consists of a nanofluidic chip based platform that allows us to run assays using TaqMan technology. Genotyping was conducted according to the manufacturer standard protocols, and genotype calls were made by Taqman Genotyper software v1.0.1. For quality control, the genotyping was performed without knowledge of the subjects' case/control status and $10 \%$ of the samples were randomly selected and genotyped twice; the rate of reproducibility was $100 \%$.

\section{Statistical analysis}

SNP genotypes identified with the Taqman Genotyper Software v1.0.1 were entered into input files for statistical analysis using the JINGLEFIX software, which also estimated minor allele frequencies (threshold $=0.05$ ) from processed data (Secolin et al., 2008). Inconsistencies with Mendelian inheritance and Hardy-Weinberg equilibrium (P value threshold $=$ 0.01) were evaluated by PEDCHECK and HAPLOVIEW software, respectively (O'Connell and Weeks, 1998; Barrett et al., 2005). We used the UNPHASED program for family-based association analysis (Dudbridge, 2008) and Bonferroni correction to account for multiple testing. To verify statistical power of our sample, we used the TDT POWER CALCULATOR program, which enables estimation from pedigrees with different family structures (Chen and Deng, 2001). Statistical power for our family sample was $>80 \%$ for the detection of an association. The parameters used in the TDT POWER CALCULATOR were: complex multifactorial trait, marker frequency $=0.10$, allele frequency $=0.25$, and a Bonferroni-adjusted statistical significance level of $\alpha=0.008$. 


\section{RESULTS}

In our analyses, we first investigated the presence of DNA insertions/deletions in 51 dyslexic and 5 normal individuals. DNA fragments generated by the MLPA reaction with each sample were analyzed, and in all cases, the electropherograms obtained showed amplification of the 40 kit probes. The same distribution patterns and peak sizes were obtained for both case and control subjects. No significant increase or decrease in the peak areas was observed in dyslexic individuals compared with the nondyslexic controls (Figure 1). Peak areas for each sample were normalized and no change was detected in probe copy numbers.

A

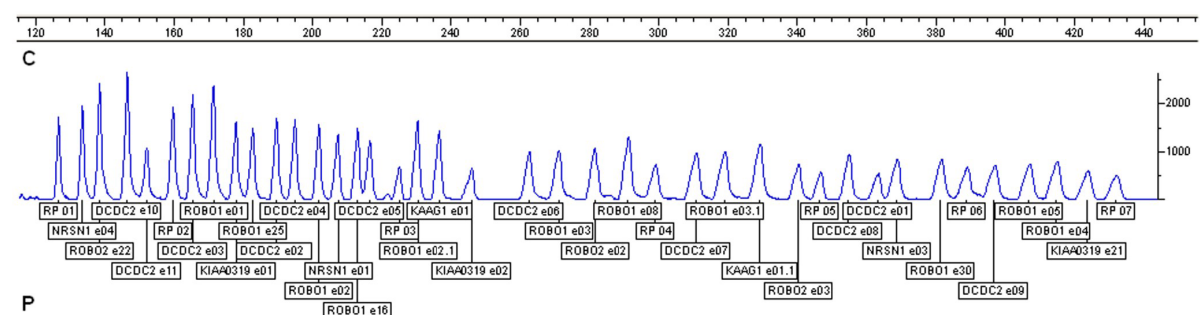

B P

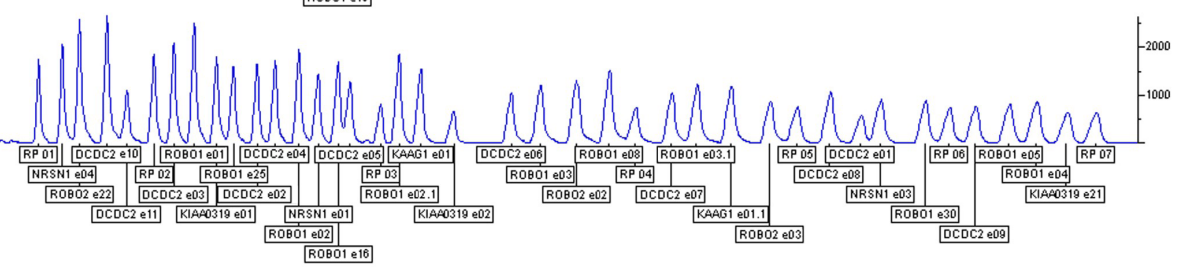

Figure 1. Electropherograms of DNA sample, obtained after MLPA reaction. Each peak represents one probe, and the probe location is shown in the text blocks. A. Nondyslexic female sample; B. dyslexic female sample.

We also conducted a family-based association study of the DCDC2 and KIAA0319 genes. As shown in Table 2, no significant association was detected for any variant in the 2 genes with dyslexia. In addition, we performed a haplotype analysis of the 3 markers in the KIAA0319 gene that had previously been associated with reading disability and detected no significant association of these 3 markers with dyslexia (global P value, 0.303 ) (data not shown).

Table 2. Family-based association results for SNPs in $6 p$ locus.

\begin{tabular}{llllll}
\hline Gene & SNP & $\chi^{2}$ & P value & OR & 95\%CI \\
\hline DCDC2 & rs807701 & 1.2 & 0.273 & 1.07 & 1.07 \\
DCDC2 & rs807724 & 0.04 & 0.852 & 1.23 & $0.52-2.22$ \\
DCDC2 & rs1419228 & 0.31 & 0.577 & 1.83 & $0.59-2.22$ \\
DCDC2 & rs9467075 & 1.49 & 0.222 & 0.56 \\
DCDC2 & rs7765678 & 0.2 & 0.654 & 0.63 & $0.5-8.98$ \\
DCDC2 & rs6922023 & 0.69 & 0.403 & 0.11 & 0.77 \\
KIAA0319 & rs6935076 & 0.11 & 0.738 & 0.71 & $0.58-2.15$ \\
KIAA0319 & rs2038137 & 0.53 & 0.465 & 1.63 & $0.34-1.57$ \\
KIAA0319 & rs9461045 & 0.87 & 0.352 & $0.67-3.92$ \\
KIAA0319d & rs2143340 & 1.2 & 0.273 & 1.12 & $0.61-2.3$ \\
KIAA0319 & rs761100 & 0.26 & 0.612 & 0.739 & $0.58-2.15$ \\
KIAA0319 & rs4504469 & 0.12 & & 1.12 \\
\hline
\end{tabular}

$\mathrm{SNP}=$ single nucleotide polymorphisms; $\chi^{2}=$ chi square; $\mathrm{OR}=$ odds ratio; $95 \% \mathrm{CI}=95 \%$ confidence interval; $\mathrm{d}=$ within TTRAP gene. 


\section{DISCUSSION}

Dyslexia can be a major challenge to learning success in schoolchildren that can initiate a downward spiral of underachievement, low self-esteem, isolation, poor mental health, and social disadvantage. Few studies have investigated this disorder in Latin America. No official data are available about the prevalence of dyslexia in the Brazilian population and no molecular genetic studies have been reported to date. Therefore, our study contributes primarily to efforts aimed at validating candidate genes for RD in samples of Latin-America origin.

This study is the first to use MLPA to investigate genetic mutations associated with dyslexia. We noted that this method was reproducible and the overall standard variation per probe was low, but our analysis did not detect any deletions or duplications in the 6 genes studied. These findings may be explained by an absence of large deletions or duplications in the studied genes that might cause the phenotype, by the presence of mutations outside the binding regions of the probes used in this study, or by a low frequency of deletions and duplications in the regions analyzed in our sample.

We are also aware of the small number of samples in our study; moreover, our results indicate a limitation of the MLPA kit P150 for mutation analysis of dyslexia. Some modification in this kit, such as changing probe locations along the genes, could lead to most promising findings. We considered it important to include probes for intronic regions for the candidate genes, to enable detection of the deletion in intron 2 of the $D C D C 2$ gene that had been reported by Meng et al. (2005). A larger screening of KIAA0319 could also be of interest, considering that this gene has 22 exons and the kit contained only 3 probes for it. We also suggest the exclusion of the KAAGI, NRSN1, and $R O B O 2$ genes, because despite being close to the major genes, these genes were not associated with dyslexia itself. Instead, the inclusion of the DYX1C1, C2ORF3, MRPL19, and KIAA0319L candidate genes in the dyslexia MLPA kit would be of greater value, because independent studies have provided significant evidence for an association of these genes with dyslexia.

We also analyzed specific variants of the DCDC2 and KIAA0319 genes that have been associated with RD in previous studies, and detected no statistically significant association between dyslexia as a categorical trait and these allelic variants. These variants probably only contribute to quantitative traits, and it is possible that phenotypic characterization and division of the sample into subgroups can lead to genetic associations.

We also tested for an association of the haplotype described by Francks et al. (2004) in the KIAA0319 gene represented by the alleles G-C-C of the markers $r s 4504469$, rs 2038137 , and $r s 2143340$ with RD; however, none of these allelic combinations was associated with RD in our sample. As described previously, studies of KIAA0319 haplotype associations with dyslexia have yielded inconsistent results. These inconsistencies may be due to the heterogeneity of $\mathrm{RD}$ and they suggest that the genetic risk variant resides on multiple haplotypes or that multiple RD-causal variants may reside on different haplotypes.

Given these results, we conclude that large gene deletions are probably not the main cause of dyslexia; however, refining the screening to include other gene regions and different candidate genes should be considered in subsequent studies. Besides, our data do not support the role of previously described variants at the DCDC2/KIAA0319 locus in affecting dyslexia as a categorical trait. Given the genetic complexity of reading disability, it is plausible that both genes contribute to risk, but that their relative influence varies in different study samples and/or depends on the analytical approaches used. 


\section{Conflicts of interest}

No competing financial interests existed.

\section{ACKNOWLEDGMENTS}

We would like to thank the families involved in this research for their cooperation and consent, and to Joaquim Pereira for his interest and collaboration with this research. Research supported by Fundação de Amparo à Pesquisa do Estado de São Paulo (FAPESP) and DresserRand Guascor Company.

\section{REFERENCES}

Achenbach TM (1991). Manual for the Child Behavior Checklist/4-18 and 1991 Profile. University of Vermont, Burlington. Anthoni H, Zucchelli M, Matsson H, Muller-Myhsok B, et al. (2007). A locus on 2p12 containing the co-regulated MRPL19 and C2ORF3 genes is associated to dyslexia. Hum. Mol. Genet. 16: 667-677.

Barrett JC, Fry B, Maller J and Daly MJ (2005). Haploview: analysis and visualization of LD and haplotype maps. Bioinformatics 21: 263-265.

Brkanac Z, Chapman NH, Matsushita MM, Chun L, et al. (2007). Evaluation of candidate genes for DYX1 and DYX2 in families with dyslexia. Am. J. Med. Genet. B Neuropsychiatr. Genet. 144B: 556-560.

Chen WM and Deng HW (2001). A general and accurate approach for computing the statistical power of the transmission disequilibrium test for complex disease genes. Genet. Epidemiol. 21: 53-67.

Cope N, Harold D, Hill G, Moskvina V, et al. (2005). Strong evidence that KIAA0319 on chromosome 6p is a susceptibility gene for developmental dyslexia. Am. J. Hum. Genet. 76: 581-591.

Couto JM, Gomez L, Wigg K, Cate-Carter T, et al. (2008). The KIAA0319-like (KIAA0319L) gene on chromosome 1p34 as a candidate for reading disabilities. J. Neurogenet. 22: 295-313.

Couto JM, Gomez L, Wigg K, Ickowicz A, et al. (2009). Association of attention-deficit/hyperactivity disorder with a candidate region for reading disabilities on chromosome 6p. Biol. Psychiatry 66: 368-375.

Couto JM, Livne-Bar I, Huang K, Xu Z, et al. (2010). Association of reading disabilities with regions marked by acetylated H3 histones in KIAA0319. Am. J. Med. Genet. B Neuropsychiatr. Genet.153B: 447-462.

Denckla MB and Rudel R (1974). Rapid "automatized" naming of pictured objects, colors, letters and numbers by normal children. Cortex 10: 186-202.

Dennis MY, Paracchini S, Scerri TS, Prokunina-Olsson L, et al. (2009). A common variant associated with dyslexia reduces expression of the KIAA0319 gene. PLoS Genet. 5: e1000436.

Dudbridge F (2008). Likelihood-based association analysis for nuclear families and unrelated subjects with missing genotype data. Hum. Hered. 66: 87-98.

Elbert A, Lovett MW, Cate-Carter T, Pitch A, et al. (2011). Genetic variation in the KIAA0319 5' region as a possible contributor to dyslexia. Behav. Genet. 41: 77-89.

Figueiredo VLM (2001). Escala de Inteligência Wechsler para Crianças (WISCIII). Casa do Psicólogo, São Paulo.

Francks C, Paracchini S, Smith SD, Richardson AJ, et al. (2004). A 77-kilobase region of chromosome 6p22.2 is associated with dyslexia in families from the United Kingdom and from the United States. Am. J. Hum. Genet. 75: 1046-1058.

Galaburda AM, Sherman GF, Rosen GD, Aboitiz F, et al. (1985). Developmental dyslexia: four consecutive patients with cortical anomalies. Ann. Neurol. 18: 222-233.

Hannula-Jouppi K, Kaminen-Ahola N, Taipale M, Eklund R, et al. (2005). The axon guidance receptor gene ROBO1 is a candidate gene for developmental dyslexia. PLoS Genet. 1: e50.

Harold D, Paracchini S, Scerri T, Dennis M, et al. (2006). Further evidence that the KIAA0319 gene confers susceptibility to developmental dyslexia. Mol. Psychiatry 11: 1085-91, 1061.

Hivert B, Liu Z, Chuang CY, Doherty P, et al. (2002). Robo1 and Robo2 are homophilic binding molecules that promote axonal growth. Mol. Cell Neurosci. 21: 534-545.

Kirsten H, Wilcke A, Ligges C, Boltze J, et al. (2012). Association study of a functional genetic variant in KIAA0319 in German dyslexics. Psychiatry Genet. 22: 216-217.

Lind PA, Luciano M, Wright MJ, Montgomery GW, et al. (2010). Dyslexia and DCDC2: normal variation in reading and spelling is associated with DCDC2 polymorphisms in an Australian population sample. Eur. J. Hum. Genet. 18: 
668-673.

Luciano M, Lind PA, Duffy DL, Castles A, et al. (2007). A haplotype spanning KIAA0319 and TTRAP is associated with normal variation in reading and spelling ability. Biol. Psychiatry 62: 811-817.

Ludwig KU, Schumacher J, Schulte-Korne G, Konig IR, et al. (2008). Investigation of the DCDC2 intron 2 deletion/ compound short tandem repeat polymorphism in a large German dyslexia sample. Psychiatry Genet. 18: 310-312.

MRC-Holland (2010). Available at [http://www.mrc-holland.com]. Accession 7 November, 2012.

Meng H, Smith SD, Hager K, Held M, et al. (2005). DCDC2 is associated with reading disability and modulates neuronal development in the brain. Proc. Natl. Acad. Sci. U. S. A. 102: 17053-17058.

Moojen S, Lamprecht RR, Santos RM, Freitas GM, et al. (2003). CONFIAS - Consciência Fonológica: Instrumento de Avaliação Seqüencial. Casa do Psicólogo, São Paulo.

Newbury DF, Paracchini S, Scerri TS, Winchester L, et al. (2011). Investigation of dyslexia and SLI risk variants in reading- and language-impaired subjects. Behav. Genet. 41: 90-104.

Nopola-Hemmi J, Taipale M, Haltia T, Lehesjoki AE, et al. (2000). Two translocations of chromosome 15q associated with dyslexia. J. Med. Genet. 37: 771-775.

O'Connell JR and Weeks DE (1998). PedCheck: a program for identification of genotype incompatibilities in linkage analysis. Am. J. Hum. Genet. 63: 259-266.

Paracchini S, Thomas A, Castro S, Lai C, et al. (2006). The chromosome 6p22 haplotype associated with dyslexia reduces the expression of KIAA0319, a novel gene involved in neuronal migration. Hum. Mol. Genet. 15: 1659-1666.

Paracchini S, Steer CD, Buckingham LL, Morris AP, et al. (2008). Association of the KIAA0319 dyslexia susceptibility gene with reading skills in the generalpopulation. Am. J. Psychiatry 165: 1576-1584.

Scerri TS, Paracchini S, Morris A, MacPhie IL, et al. (2010). Identification of candidate genes for dyslexia susceptibility on chromosome 18. PLoS One 5: e13712.

Scerri TS, Morris AP, Buckingham LL, Newbury DF, et al. (2011). DCDC2, KIAA0319 and CMIP are associated with reading-related traits. Biol. Psychiatry 70: 237-245.

Schumacher J, Hoffmann P, Schmal C, Schulte-Korne G, et al. (2007). Genetics of dyslexia: the evolving landscape. $J$. Med. Genet. 44: 289-297.

Schouten JP, Mcelgunn CJ, Waaijer R, Zwijnenburg D, et al. (2002). Relative quantification of 40 nucleic acid sequences by multiplex ligation-dependent probe amplification. Nucleic Acids Res. 30: e57.

Secolin R, Rocha CS, Torres FR, Santos ML, et al. (2008). LINKGEN: a new algorithm to process data in genetic linkage studies. Genomics 91: 544-547.

Sisto FF, Noronha APP and Santos AAA (2005). Teste Gestáltico Visomotor de Bender - Sistema de Pontuação Gradual (B-SPG). Vetor, São Paulo.

Snowling MJ and Maughen B (2006). Reading and Other Learning Disorders. In: Cambridge University Press, Cambridge, 446-417.

Stroop JR (1935). Studies of interference in serial verbal reactions. J. Exp. Psychol. 18: 643-662.

Taylor CF, Charlton RS, Burn J, Sheridan E, et al. (2003). Genomic deletions in MSH2 or MLH1 are a frequent cause of hereditary non-polyposis colorectal cancer: identification of novel and recurrent deletions by MLPA. Hum. Mutat. 22: 428-433.

Venkatesh SK, Siddaiah A, Padakannaya P and Ramachandra NB (2011). An examination of candidate gene SNPs for dyslexia in an Indian sample. Behav. Genet. 41: 105-109.

Wang Y, Paramasivam M, Thomas A, Bai J, et al. (2006). DYX1C1 functions in neuronal migration in developing neocortex. Neuroscience 143: 515-522.

Wilcke A, Weissfuss J, Kirsten H, Wolfram G, et al. (2009). The role of gene DCDC2 in German dyslexics. Ann. Dyslexia 59: 1-11. 